Cronfa - Swansea University Open Access Repository

This is an author produced version of a paper published in :

Public Management Review

Cronfa URL for this paper:

http://cronfa.swan.ac.uk/Record/cronfa18523

\title{
Paper:
}

Allen, P., Hughes, D., Vincent-Jones, P., Petsoulas, C., Doheny, S. \& Roberts, J. (2016). Public Contracts as Accountability Mechanisms: Assuring quality in public health care in England and Wales. Public Management Review, 18(1), 20-39.

http://dx.doi.org/10.1080/14719037.2014.957341

This article is brought to you by Swansea University. Any person downloading material is agreeing to abide by the terms of the repository licence. Authors are personally responsible for adhering to publisher restrictions or conditions. When uploading content they are required to comply with their publisher agreement and the SHERPA RoMEO database to judge whether or not it is copyright safe to add this version of the paper to this repository. http://www.swansea.ac.uk/iss/researchsupport/cronfa-support/ 


\section{Public contracts as accountability mechanisms: assuring quality in public healthcare in England and Wales}

Dr Pauline Allen*, Department of Health Services Research and Policy, London School of Hygiene and Tropical Medicine, 15/17 Tavistock Place, London WC1H

email: pauline.allen@1shtm.ac.uk

Professor David Hughes, Department of Public Health \& Policy Studies, Swansea University, Swansea

Email: d.hughes@swansea.ac.uk

Professor Peter Vincent-Jones, School of Law, University of Sheffield, Sheffield

Email: p.vincent-jones@sheffield.ac.uk

Dr Christina Petsoulas, Department of Health Services Research and Policy, London School of Hygiene and Tropical Medicine, London

Email: Christina.Petsoulas@1shtm.ac.uk

Dr Shane Doheny, School of Planning and Geography, Cardiff University, Cardiff

Email: DohenyS1@Cardiff.ac.uk 
Professor Jennifer A Roberts, Department of Health Services Research and Policy, London School of Hygiene and Tropical Medicine, London

(Professor Roberts died in April 2014)

*Corresponding author 


\section{Public contracts as accountability mechanisms: assuring quality in public healthcare in England and Wales}

\section{Third revision July 14}

$\underline{\text { Introduction }}$

One of the aims of the New Public Management (NPM) was to improve the quality of public services through the contractualisation of relationships involved in their delivery. Contracts were a key feature of the internal market introduced into the English and Welsh National Health Services (NHS) in the early 1990s, entailing the splitting of responsibilities for the purchasing and provision of health care (DH, 1989). As well as serving as instruments of control and regulation (Vincent-Jones 2006), contracts may also be regarded as mechanisms for increasing the accountability of those delivering the services to funders and users (Hodge and Coghill, 2007; Bovens, 2006; Maybin et al, 2011; Scott, 2000; Craig, 1994). Whereas accountability in the NHS was traditionally based on a professional agency model, in which self-regulating experts were trusted to make decisions on behalf of patients and the public, this has increasingly been displaced by a contractual model involving bureaucratic scrutiny and challenge (Tuohy 2003, p. 199). Contractualisation re-frames the relationship so that the provider is cast as an agent working to fulfil requirements set by a commissioning organisation acting as principal (Figueras et al 2005). A driving force behind NPM has 
been to sharpen accountability by harnessing the capacity of contracts for 'defining goals, setting targets and monitoring performance' (Craig 1994; p. 110).

This paper analyses the problems encountered in the attempt to use contract as an accountability mechanism with reference to the results of a comparative study of contracting for healthcare in England and Wales, two countries whose NHS policies have been on increasingly divergent trajectories, while continuing to share the core principle that health care is free at the point of delivery and financed from general taxation. The introduction of quasi- markets for healthcare in both countries in the 1990s did not change this principle: the market was only in respect of competition between providers, and did not affect financing from the point of view of patients (Le Grand and Bartlett, 1993). Despite some initial moves to soften the internal market introduced under the previous Conservative Government, the New Labour administration of the early 2000s took only a few years to reintroduce policies based on markets and competition in the English NHS, thus opening up differences with the other home countries (see Mays et al. 2011). In the English quasi-market that existed until April 2013, public bodies named Primary Care Trusts (PCTs) commissioned services from an expanding range of state and independent sector providers, including NHS trusts, private corporations and charitable bodies ${ }^{1}$. A standard national contract was introduced in 2007 , intended by the government to serve as 'an important tool for assuring accountability between providers and PCTs and for improving performance' (DH 2007, p.4). By contrast, policy in Wales has moved closer to the vision of an integrated state service. In the early 2000s following devolution, Wales adapted the original 1990s internal market model by encouraging purchasers and providers to work co-operatively in a system with strong elements of planning and better co-ordination

\footnotetext{
${ }^{1}$ The recent policy changes introduced by the Health and Social Care Act 2012 are discussed later in the paper.
} 
between health, local government and the voluntary sector. By 2006 the Welsh NHS was using a softer version of commissioning based on 'collegiate contracting' in Secondary Care Commissioning Groups, which later evolved into a system where Local Health Boards (LHBs) were supported by three Regional Commissioning Units. LHBs still purchased treatments via NHS contracts, but did so within a framework which emphasized planning. The LHBs' contracts - their Long Term Agreements - meshed with an Annual Operating Framework (AOF) agreed with one of three Welsh Assembly Government (WAG) Regional Offices. (See figures 1 and 2 for diagrams of the respective English and Welsh structures.)

\section{Insert figures 1 and 2 here}

These differences in the organisation of healthcare in England and Wales are important and may be accentuated further in future. The trend towards increasing commercialisation in England continues through the greater emphasis on market mechanisms and the funding of non-NHS providers of care to NHS patients under the Health and Social Care Act 2012. In Wales, the Labour and Plaid Cymru Parties entered a coalition agreement in 2007 which pledged to end the internal market and eventually resulted in the abolition of the purchaser/provider split in April 2009. Nevertheless, in the relevant research period for this paper, the objective of improving performance through contractual accountability in some form was part of government policy in both countries. The contrasting types of contracts offer a rich source of data for empirical investigation of the accountability dimensions of contractual governance. 
The paper is structured as follows. The next section shows how the introduction of contracts in the NHS was seen by policy makers as contributing to improved efficiency and quality in healthcare provision by increasing the accountability of service providers to commissioners, service users and citizens. Drawing on socio-legal and economic theories of contracting, the inherent limitations of contract in performing key accountability tasks are analysed in the broader context of other accountability mechanisms which were also introduced as part of the NPM. This section introduces the concept of redundancy, which will be used later in exploring the relationship between different and potentially complementary accountability institutions in the NHS. The subsequent section applies this theoretical perspective in analysing the results of an empirical study of contracting in the English and Welsh NHS. The final section offers some conclusions and explores implications for the future of the NHS and public services generally.

\section{Contracts as a means to improve accountability in the National Health Service}

\section{Accountability}

The term 'accountability' has expanded to include a variety of meanings beyond the basic sense of being called to account for one's actions (Mulgan 2000). The most useful definition for the purposes of this paper is 'a relationship between an actor and a forum, in which the actor has an obligation to explain and to justify his or her conduct, the forum can pose questions and pass judgement and the actor may face consequences' (Bovens 2006, referred to in Bovens et al. 2008). This definition captures the 'original core of accountability signifying external scrutiny, justification, sanctions and control' (Mulgan 2000, p. 557). A distinction may be drawn between political accountability and administrative or 
managerial accountability; the former concerned with the accountability of Ministers and the government to the electorate, and the latter focusing on the stewardship of public funds and on mechanisms for ensuring efficiency and probity in public spending (Day and Klein 1987; Loughlin 1992). While these forms of accountability are closely related in the NHS, our focus in this paper is on the latter, performance dimensions associated with quasi-market contracting.

Several aspects of this type of accountability may be identified (Leat 1988): fiscal, which concerns financial probity and thus the ability to trace and adequately explain all expenditure; process, which concerns the use of proper procedures; programme, which concerns the activities undertaken and, in particular, their quality; and finally, priorities, which concerns the relevance or appropriateness of the activities chosen. This paper focuses on quality of care as an aspect of programme accountability in the NHS. There have been many attempts to define what is meant by the quality of care over the years (e.g. Donabedian, 1980; Berwick, 1990; Campbell et al, 2000). For the purposes of this paper we use the operative definitions and measures of quality employed by the commissioners themselves; an approach that we discuss in more detail in the findings section below. Quality is an interesting domain because it is an area where contractual governance intersects with other modalities of control in the form of hierarchical performance management and clinical governance. The focus on quality issues is particularly valuable in highlighting certain problems in using contracts to achieve accountability in a public service provided by professionals.

In quasi-markets for public services (Le Grand and Bartlett 1993), contracts may be seen as carrying out four key accountability tasks: setting standards against which to judge accounts; obtaining accounts; judging accounts; and deciding what consequences should follow (Davies 2001). Because in this type of contractual relationship services are purchased by public agencies on behalf of citizens who are not privy to the 
purchaser/provider contract, it is important that the accountability of the provider to the commissioning authority is considered in the wider context of accountability to the public (Demirag and Khadaroo 2008).

\section{Theories of contract}

In economic theory, one problem with the use of contract as an accountability mechanism is how to ensure that the agent (in this case the service provider) acts in the interests of the principal (commissioner). In circumstances of imperfect information, once responsibilities are delegated, it is possible for agents to make decisions which will further their own ends, rather than those of principals (Jensen and Meckling 1976). A related problem is that even simple contracts are necessarily incomplete and incapable of specifying all contingencies and eventualities at the outset. An extensive economic and socio-legal literature has shown the impossibility of 'complete' planning in practice in respect of complex products or services (Macneil 1978; Williamson 1985). Parties to long-term contractual relationships often do not even attempt to specify their contractual relationships completely (Macaulay 1963; Beale and Dugdale 1975). This is due to high transaction costs (TCs) associated with imperfect information, either about the other party involved in the exchange (asymmetric information) or about the future (uncertainty). Long-term relationships are likely to develop in circumstances where there is little or no choice of contracting partner (Williamson, 1985). Given such conditions, the contract may be left deliberately incomplete and provide instead for flexibility in renegotiation and implementation (Campbell and Harris, 1993). To the extent that important elements in performance cannot be fully specified or monitored, there are inherent limitations in the use of contracts as instruments for enhancing accountability. Such problems have been highlighted by researchers internationally in relation to healthcare (e.g. Palmer and Mills 2003; Allen 2002; Ashton 1998; Hughes et al. 1996), confirming the limitations of contracts in 
accomplishing key accountability tasks of setting standards and monitoring performance (Craig 1994). Studies of contracting for healthcare also note that other mechanisms have been used to supplement contracts in achieving accountability. In the early NHS internal market in England and Wales in the 1990s, enduring top down hierarchical structures have been observed as a mechanism used by the state to improve accountability of providers (Allen, 2002; Hughes and McHale, 1996). Moreover, general contract theory indicates that network (or clan) relationships between individuals in different contracting organisations can also enhance accountability (Ouchi, 1979). Studies of healthcare have noted the existence of strong networks between healthcare professionals reaching across organisational boundaries (Allen, 2002; Sheaff et al, 2010).

Socio-legal theory casts further light on problems with contractual accountability. According to Macneil (1978), contractual exchange is underpinned by a combination of 'discrete' norms such as consent and choice that are necessary for planning, and relational norms such as flexibility and reciprocity that are essential to support trust and cooperation in the implementation of the contract. Both sets of norms are involved in all NHS contracting relationships (Petsoulas et al. 2011). Where contractual relations are operating effectively, the discrete and relational norms are over time likely to be in approximate balance. By contrast, adversarial relations are predicted where the discrete norms involved in contract planning have become unduly accentuated, at the expense of the relational norms (Vincent-Jones 2006). Contractual exchanges may be regarded as 'relational' to the extent that they reflect such a balance, thereby creating the conditions for the attainment of joint welfare-maximising benefits associated with optimal private sector transactions, and enabling the gaps in necessarily incomplete contracts to be filled (Campbell and Harris 1993). This should not be taken to mean that relational norms are more important than discrete norms: providers of care may act opportunistically in some circumstances, and on these occasions less trusting behaviour by commissioners is required, with closer 
attention to the discrete norms and greater efforts in monitoring providers' performance (Seal and Vincent-Jones 1997; Lonsdale 2010). Sociolegal studies confirm the crucial role of relational norms in determining the quality of outputs in contracting for public services such as social services (Schmid, 2003). Relationality may be difficult to achieve in quasi-market exchanges where the delivery of services (for example due to high asset specificity, asymmetric information and uncertainty) might better have been achieved through vertical integration (Petsoulas et al. 2011). Where relational conditions are absent or are undermined, it cannot be expected that contracts will operate effectively as accountability mechanisms (Duberley and Johnson, 1999). In accountability terms, a relational contract is one in which the parties responsible for calling to account, and those called upon to give account, act in a fair and reasonable manner in discharging their respective obligations.

\section{Combining accountability mechanisms: redundancy}

The introduction of internal market contracts was not the only means adopted by the New Labour government for improving accountability in the NHS. Modernisation strategies focused also on standard-setting coupled with the use of centrally-defined targets and performance management (Bevan and Hood, 2006). Several methods to improve accountability in respect of quality and safety of healthcare were used concurrently. A system of nationally-imposed and monitored performance targets for all providers was introduced under the Health Act 1999, most notably for issues such as reducing hospital acquired infections and reducing inpatient waiting times (Department of Health 2009). In addition, national regulators and inspectors, operating at arms-length from government, were given a role in inspecting and enforcing these quality standards: Monitor in respect of some more autonomous NHS Trusts (Foundation Trusts); and the (now expanded) Care Quality Commission (originally Commission for Healthcare Improvement) in respect of all providers to NHS patients. In contrast to the arms-length 
approach, the WAG established Healthcare Inspectorate Wales in 2004 as a division of a government department, to take responsibility for reviewing quality and inspecting NHS and independent healthcare organisations in the Principality.

One innovation specifically designed to improve accountability for the quality of care was clinical governance (Secretary of State 1998). The aim of clinical governance (as opposed to liability in negligence, for example) is to hold groups of healthcare professionals accountable for each other, thereby adding to the existing and continuing notion of the accountability of individual professionals for their own behaviour both in law to their patients and to their respective professional bodies. This is a variant of Tuohy's (2003) traditional 'agency model' of accountability, but, in this case, paradoxically being imposed from outside the professions. Clinical governance illustrates how in the modern state the dyad of principal and professional agent is nested within multiple cross-cutting regulatory structures.

The deployment of multiple instruments for enhancing accountability in the NHS may usefully be considered in terms of Scott's (2000) concept of 'redundancy', referring to a situation in which 'overlapping (and ostensibly superfluous) accountability mechanisms reduce the centrality of any one of them' (p. 52). Scott regards this 'belt and braces' (p. 53) approach to accountability as the product of a mixture of deliberate design and contingency: the former due to an appreciation of the scale of risks, and the latter being an unintended effect of particular institutional configurations. The concept of redundancy will be applied at various points in the remainder of the paper in analysing the complex system of accountability in the NHS.

Our study of contracting in the English and Welsh NHS 
Our research was designed to find out the extent to which contracts in England and Wales respectively could be used by commissioners to promote and achieve accountability on the part of providers of healthcare, and the extent to which other mechanisms were used. The design comprised two English and two Welsh case studies, carried out between 2007 and 2009 to compare the processes of NHS contracting in the two countries. Each case study investigated the ongoing relationships between an NHS purchasing body - a Primary Care Trust (PCT) or Local Health Board (LHB) - and its network of providers. The two pairs each included a predominantly urban area and a more mixed urban/rural area, with the urban case studies including a major teaching hospital and the mixed cases only district general hospitals. This combination of characteristics was selected to allow us to assess whether contracting in larger conurbations, with two or more hospitals, differed from contracting in mixed localities with fewer providers. Economic theory suggests that long-term relationships and associated relational norms are particularly likely to develop in circumstances with reduced competition and fewer contractual partners (Williamson 1985). In the event, however, we did not find major differences between the types of sites. Nor did we find significant differences between types of respondent or organisation. Each case study site involved a commissioner of care, the network of main provider hospital trusts, and the overseeing authority relevant to each country. The case studies consisted of a mix of observation of meetings (36 in England, 48 in Wales), interviews with key contracting personnel in commissioning and provider organisations (24 in England, 64 in Wales), and analysis of documents, being mainly contracts themselves and other planning documents. For each country, we also completed semi structured interviews with the relevant overseeing authorities. Interviewees were selected on the basis of their key role in contracting: Finance Directors, Commissioning and 
Contracting Directors and Managers, Directors of Operations and Nursing Directors, Directors of Quality and Safety, IT Managers and consultants. Some managers had clinical qualifications, but in general healthcare professionals had a peripheral involvement in contracting. The topics for the interviews were derived from the key aspects of socio-legal and economic theories of contracts discussed in the theory section above. Since existing evidence (and theories of contracting for healthcare) indicated that professional networks and hierarchical mechanisms would also be salient, these were included as well. The topics we explored included: how performance was specified in the contracts; how performance was monitored against such specifications; whether the provisions of the written contract were adhered to in practice, including in particular the allocation of financial risk; how any disputes between the parties were handled; how variations to written contractual provisions were dealt with (i.e. formally in writing or not); the duration and importance of personal relationships between the contracting leads working for the contracting parties; the influence of higher levels of the NHS hierarchy on the parties; and the extent and content of professional networks spanning boundaries between commissioner and provider organisations. The same topics were explored when observing contracting meetings. Interviews were recorded and transcribed. Meetings observed were recorded and transcribed verbatim, and contemporaneous field notes were also made by the member of the research team making the observation in order to capture the most salient aspects of the meeting. We analysed the interview and meeting transcripts using the socio-legal and economic theories of contract discussed above and, in order to do this, we used the topics discussed earlier in this section. This meant that we were focusing on the problematic aspects of contracting, namely: specification of performance, monitoring performance, and enforcement of contractual provisions, as well as the alternative mechanisms of professional networks and hierarchy. 
Findings

The findings presented here relate to the use of health service contracts to promote accountability in respect of quality of care in England and Wales.

a) Specifying contractual performance

The use of formal contractual provisions to set standards and specify contractual performance differed markedly in the two NHS systems. There was a greater emphasis in England on using contractual mechanisms to provide incentives for improving quality of care. Contracts in Wales were less detailed, with greater reliance on parallel management arrangements. Arguably the redundancy implicit in this twin-track approach reflected the transitory nature of the arrangement. Contracts were abolished in the Welsh NHS in 2009. The reasons were manifold and included a political preference for an integrated NHS over a market-based system, a national geography that left many rural areas with a single monopoly provider and little scope for competition, and a perception that the quasi-market was an artificial creation that required continued central steering and incurred substantial transaction costs. With the old system winding down, contracting played a small and diminishing part in specifying performance standards in Wales.

As has been seen, the introduction of the standard national contract in England in 2007 was expressly intended as an accountability mechanism for improving service quality. The associated Commissioning for Quality and Innovation (CQUIN) initiative included proposals for increased use of contractual financial incentives and penalties (DH 2008). The contract document was drafted centrally and, while leaving room for locally 
negotiated targets, also contained a number of 'mandatory and non-variable' clauses, such as those concerning national targets (DH 2007). The financial incentives were specifically designed to improve quality of care. An example of a CQUIN indicators from our case studies is the reduction to delays in patient discharges. For 2009-10, government guidelines allowed for up to $0.5 \%$ of the total contract value to be attached to achieving the CQUIN targets. In addition to the CQUIN scheme, commissioners were encouraged to include other locally-agreed quality targets in the contract. The contract also specified financial penalties for failure to meet national quality targets, as well as allowing penalties for breaches of locally-agreed targets. By contrast, Welsh contracts (or LTAs) did not generally contain quality appendices or other detailed clauses specifying performance standards; instead, more faith was placed on clinical governance and performance management (WAG 2005). The LTAs did reflect the targets and priorities set out by the WAG in the Annual Operating Framework (AOF), but the detail of these expectations was specified outside the contractual documents. Once it became clear in 2007, following the publication of the Labour/Plaid Cymru One Wales Agreement, that contracting was to be abolished in Wales, commissioning staff realised that there would be little possibility of holding providers accountable for non-performance, and in consequence, many contracts took a looser block form, leading to a winding down of the previous contract monitoring arrangements. While most LTAs contained provision to claw back monies for under-performance on activity, no financial penalties were included for contract breaches relating to quality, for example, in relation to long waiting times or infections.

b) Monitoring contractual performance 
In both England and Wales, it was apparent that, as predicted by the theories of contract discussed above, commissioners found it difficult to monitor some aspects of contractual performance and therefore to obtain accounts concerning the quality of service provision, due to serious asymmetries in information between commissioners and providers. This meant that, regardless of the degree of formality of contract documents and whether penalties/incentives were contractually specified, in neither country could the contract be used as the primary mechanism to achieve accountability for quality of care.

In England, the intended benefits of greater formality and specificity in contracts could not be realized in the absence of accurate and detailed performance data. But where data about quality were available, the contractual requirement to generate those data had contributed to improving the quality of care.

So we've split that, patient safety, patient quality, patient experience and innovation, developed our objectives through that and key performance indicators and a framework for monitoring the performance and outcomes for patients and then looking at what that provides assurance against or evidence towards... So that's new and that's just currently being embedded. It's already started for a couple of months and it's given us greater assurance around patient safety and quality. (NHS Trust, Director of Nursing)

Welsh informants also complained that rigorous contract monitoring was difficult in the absence of a reliable information base.

Where if you like I think it is a bit weak is we have got a lot of information around activity, we have got a lot of information around finance, we have got a lot of information around performance (...) because it is countable to a large degree, you know measurable. I 
think with hindsight I would say we were fairly weak on the quality stuff. [...] I don't think it is actually explicit enough in terms of what we want to measure in terms of quality this is how it will be monitored and this is what we will do if it goes awry. (Director of Finance, LHB )

\section{c) Enforcement of contracts}

Although the English contract, in particular, gave commissioners various financial levers with which to enforce accountability for quality, we found that not all were used in practice. One of the reasons for this was the difficulty in monitoring quality, as discussed above. Another is more complex. As contracts for healthcare in England were incomplete, the parties relied on relational norms to operate them effectively. These relational norms included flexibility (namely avoiding rigidity and facilitating adaptation to changing conditions) and reciprocity (Vincent-Jones 2006). The effect of adhering to these norms was to constrain the use of financial penalties, which might have damaged the long-term relationships between the parties. These relationships were important to foster and maintain the high levels of trust and co-operation required in the absence of a complete contract. Moreover, health service contracts need to be seen in their institutional context: they operated in an internal market, where hierarchical elements were still very salient (Hughes et al. 2011).

In England, for example, we found that when there was a possibility of taking a dispute about quality of data to a formal arbitration, which could have imposed financial penalties on the provider, the commissioners did not do so. 
In Wales, commissioners chose not to include penalty clauses in contracts, even where the national LTA template made provision for this. As our interviews showed, senior NHS management felt that the use of contractual penalties had 'withered away' in Wales. Use of local penalties in LTAs had not in practice been encouraged by the centre:

The only areas with penalties (..) the only one that was protected was provision of information. [There were] potential penalties...I'm struggling to remember what they were, but basically we were told anecdotally don't implement them, you won't be supported. (Director of Finance. LHB ).

d) Reliance on professional relationships

An example of the relevance of the traditional agency model of regulation (Tuohy 2003) in the healthcare field is the use of professional networks by clinicians to improve quality of care. We found that clinical networks were developing in both England and Wales, and that these were performing increasingly important roles in ensuring accountability for quality of care. Interviewees in England referred to the existence of a number of clinical networks which were involved in monitoring quality.

There were also indications in Wales that clinical networks were becoming important. The 2007 commissioning guidance had envisaged that the networks would provide clinical support for the Regional Commissioning Units (RCUs), including by aligning commissioning more closely with standardised patient pathways and greater attention to quality. By the end of the research period there were indications that this was starting to 
happen, albeit with different networks using different approaches. Thus the Cancer Network had produced a set of minimum cancer standards and a detailed quality specification for upper gastro intestinal cancer, while the renal network had introduced quality audit and was seeking to align treatments more closely with the interventions promoted by the Welsh Assembly Government's '1000 Lives' patient safety campaign. .

However, news of the end of the internal market (and thus commissioning and contracting) meant that service specifications developed by the clinical networks did not figure in the simplified LTAs written as purchasers and providers prepared for the new integrated health authorities.

e) Use of other regulatory mechanisms - redundancy

A key theme to emerge from the research concerned the importance of the wider institutional context of NHS contracts in England and Wales. As discussed above, the complexity of the regulatory environment of healthcare may usefully be analysed in terms of the 'redundancy' of accountability mechanisms posited by Scott (2000). This concept is valuable in highlighting both the limits of contract in performing key accountability tasks, and the role of other forms of regulation which operated in conjunction with contracts in maintaining service quality.

For example, our study uncovered instances of the use of hierarchical mechanisms to achieve accountability for quality which, certainly in the case of Wales, were more significant than contracts. The sanctions for poor performance were not financial - instead, the organisation could be put in 'special measures' (i.e. increasing gradations of external management).

Even in England, where more reliance was placed on the detailed standard contract, PCT and Trust interviewees made it clear that performance management from higher tiers in the NHS hierarchy was vital in their efforts to improve quality. In any event, the standard contract itself was 
mainly a means to enforce nationally-set targets. Furthermore, in the case of Foundation Trusts, the regulator (Monitor) performs a range of accountability functions in setting, monitoring and enforcing standards.

It is arguable that this performance management facet of redundancy is due more to contingency than deliberate design (Scott, 2000). It appears to be the effect of existing institutional configurations, namely the fact that the NHS in England and Wales has been since its inception a centralised, hierarchical system in which upper levels of the government hierarchy have a large degree of authority over local organisations.

On the other hand, the independent regulator of quality of care in England (the Care Quality Commission (previously the Healthcare Commission) and its counterpart Healthcare Inspectorate Wales were not seen as the dominant actors in shaping the direction of regulation in either country. Hierarchical performance management was the primary mechanism used to steer the direction of reform in both countries.

\section{Summary of findings}

The comparison of England and Wales's use of contracts to achieve accountability for quality of care in their respective NHS systems demonstrates that, although there was a much greater emphasis on the use of detailed contractual documents in England (as opposed to other hierarchical mechanisms in Wales), the results were similar. Contracts in both countries may be regarded as having failed adequately to perform key accountability tasks of setting standards, obtaining accounts, and enabling enforcement in respect of key aspects of quality. Some of the deficiencies in contractual governance were made up for in both countries by the use of hierarchical mechanisms. 


\section{Conclusions}

As the paper is based on only four case studies, we acknowledge that it has limitations in terms of statistical generalisability. However, a case study design was the appropriate research method to enable us to obtain opinions and perceptions from various perspectives in particular institutional contexts (Keen and Packwood, 1995). Case studies allow a form of analytic generalisation, as opposed to statistical generalisation. Analytic generalisation uses the previously developed theory as a template with which to compare the empirical results of the case study (Yin, 2003).

The evidence presented in this paper confirms the limitations suggested by economic and socio-legal theory in the use of public contracts as mechanisms for achieving accountability for quality in healthcare. We have seen how the complexity of the relationships involved in the provision of human services makes particularly problematic the attempt to harness contract to this end, as Lane predicted in 1999. Craig (1994) claimed that using contracts would enable public servants to set targets and monitor performance. But we have seen that target setting, and performance monitoring in particular, are difficult to achieve in the case of healthcare. As Tuohy (2003) points out, much is expected of information technology to deliver contractual accountability, but it has limits in practice. The comparison of the contracts in England and Wales 
in our study allows us to conclude that attempting to specify contractual performance in greater detail (as in England) did not resolve matters: monitoring of performance was still problematic.

These conclusions have important implications for the future of the English NHS, in particular. Current policies set out in the Health and Social Care Act 2012 are aimed at increasing marketisation. In addition to enhancing competition and the powers of regulators, it is envisaged by the Coalition government that the number of non-NHS providers of care will increase greatly. Some of the alternative regulatory mechanisms, such as exercise of authority through the NHS hierarchy, will not apply to these organisations which are outside the direct control of the state.

Although they will be subject to other forms of economic and quality regulation (by Monitor and the Care Quality Commission respectively), the accountability of such bodies in the new English NHS architecture will be heavily dependent on the contract mechanism. As we have demonstrated in this paper, it is unwise to rely on contracts to ensure accountability of providers of care, especially in relation to quality of care. Moreover, the current policy envisages that NHS-owned providers of care will be granted greater autonomy from central control (by becoming NHS Foundation Trusts, which are a specific form of state owned healthcare provider not subject to direct command from the NHS hierarchy; see Allen et al. 2011), so that the institutional framework which enables contractual problems to be solved using hierarchical performance management will not be available in its current form.

Wales is pursuing a different route involving an enhanced patient safety framework - ' 1000 Lives Plus' - and updated healthcare standards enforced through self-assessment supported by testing and validation by Healthcare Inspectorate Wales (NHS Wales, 2010). A mixed governance system involving performance management, clinical governance and contractual governance has been simplified to dispense with 
this last component. The new policy is characterised by a sharper focus on patient experience and citizen voice. Its success will depend on the service's ability to make progress on the public engagement front in a period of economic retrenchment and increasing centralisation of power, but these issues are beyond the scope of the present paper. Moreover, as we discuss below, hierarchical forms of standard setting and performance management are not without difficulties themselves.

It may further be suggested that the increasingly central role of contracts in the organisation of public services entails an inappropriate extension of economic reasoning which has undermined political and communal accountability (Seal and Vincent-Jones 1997). The various problems associated with the attempt to use contract to enhance accountability in the NHS are mirrored by the experience of contracting in other public service contexts where accountability goals have not been achieved (e.g. local authorities' services; Duberley and Johnson, 1999). Nevertheless, the potential value of contracts as one among a number of mechanisms for promoting accountability cannot be dismissed altogether. Our study shows that setting standards in contracts and collecting information about performance, where this has been possible, can have beneficial effects in accountability terms, as increased knowledge about contractual performance can allow commissioners better to judge the quality of care delivered, and to remedy poor performance. The comparison of England's policy of gathering increasingly detailed performance data with Wales's less dogmatic approach is instructive. Thus, there is some truth in the claims that contracting processes, with their increased capacity for data collection and transfer, can help enhance accountability (Craig 1994; Tuohy 2003). In particular, the use of contractual mechanisms makes it easier to enhance fiscal (i.e. budgetary) accountability, as the monitoring of financial performance does not entail the same level of difficulty as specifying, measuring and monitoring the quality of care provided (Petsoulas et al, 2011). 
We should also note that standard setting and performance monitoring are also problematic in non-contractual, hierarchical settings. Difficulties in obtaining sufficient information to carry out adequate monitoring are not peculiar to contract. Whatever the technique employed,

accountability may be impeded by information asymmetries and by gaming on the part of those being monitored in reporting their performance (Bevan and Hood 2006). Nevertheless, there is evidence that performance measurement systems have become more sophisticated over the years, and that they can capture useful information about the outcomes of care, if constructed carefully (Jacobs et al, 2004). This confirms the value of conceiving of accountability in the NHS in terms of redundancy (Scott 2000). A successful strategy is likely to require the combination of accountability mechanisms in this field. The implication is that we should not aim necessarily to simplify regulatory structures, but rather to achieve the correct tension between different regulators, modes of regulation, and lines of accountability. However, it is difficult in practice to know which regulatory structures are beneficial, and which are not, and if they can in fact co-exist effectively. An example of the problematic interplay of accountability mechanisms is that involved in patient safety. The existence of legal accountability of professionals and their employers under the doctrine of professional negligence, which leads to great caution in admitting mistakes, can conflict with the aim of using an open, learning approach by using professionals' mistakes to build up a safety culture (Dodds and Kodate 2011).

The discussion of the use of contracts to achieve accountability in this paper allows us to draw more general conclusions about the New Public Management. NPM is based on the premise that using mechanisms in the public sector similar to those employed in private markets (such as contracts) will enable us to improve key aspects of performance - efficiency, quality and accountability. But the complexity of human services, together with the difficulties inherent in attempting to specify and measure them (Hughes 1998; Lane, 1999), are the main reason why these 
mechanisms are not found in the public sector in the first place. The paradox in the use of contracts lies in their reliance on processes of specification and monitoring which are inherently difficult to implement effectively in this context (Jackson, 2001). This paradox and its effects may well explain why new theories of public administration and management have been developed in recent years under the rubric of 'New Public Governance' (NPG) (Osborne, 2006). NPG theories recognise that there is now both a plural state and a pluralist state: 'multiple interdependent actors contribute to the delivery of public services and [...] multiple processes inform the policy making system' (Osborne, 2006, p 384). Thus, while it is probably too late to return to the old paradigm of state delivered public services (classic 'Public Administration'), recent evolution of public administration and management has taken it beyond NPM to NPG, in which a plurality of actors and 'inter-organizational relationships where trust, relational capital and relational contracts act as core governance mechanisms' (Osborne, 2006, p 384). Our study demonstrates that relational contracting is indeed a major form of governance for health services in England and Wales.

\section{$\underline{\text { References }}$}

Allen, P. 2002. 'A socio-legal and economic analysis of contracting in the NHS internal market using a case study of contracting for district nursing', Social Science and Medicine 54, 2 255-266

Allen, P., Bartlett, W., Perotin, V., Zamora, B. and Turner, S. 2011. 'New forms of provider in the English National Health Service', Annals of Public and Cooperative Economics 82, 1 77-95

Ashton, T. 1998. 'Contracting for health services in New Zealand: a transaction cost analysis', Social Science and Medicine 46, 3, 357-367 
Beale H., and T. Dugdale. 1975. 'Contracts between Businessmen', British Journal of Law and Society 2, 45-60

Berwick DM, Godfrey AB, Roessner J (1990). Curing health care: new strategies for quality improvement. A report on the National Demonstration Project on Quality Improvement in Health Care. San Francisco: Jossey-Bass.

Bevan, G. and C. Hood. 2006. 'Have targets improved performance in the English NHS?', British Medical Journal 332, 419-22

Bovens, M. 2006. Analysing and Assessing Public Accountability. A Conceptual Framework European Governance Papers (EUROGOV) No C06-01

Bovens, M., Schillemans, T. and P. ‘T Hart. 2008. 'Does public accountability work?’, Public Administration 86,1, 225-242

Campbell, D. and D. Harris. 1993. 'Flexibility in long term contractual relationships: the role of co-operation', Journal of Law and Society 20, 166-191

Campbell, S., Roland, M., Buetow, S. (2000) 'Defining quality of care' Social Science and Medicine 51 (11) 1611-1625

Craig, G. 1994. Administrative Law ( $3^{\text {rd }}$ Ed). London: Sweet and Maxwell

Davies, A. 2001. Accountability: a public law analysis of government by contract, Oxford: Oxford University Press

Davis, P. 2007. 'The effectiveness of relational contracting in a temporary public organisation: intensive collaboration between an English local authority and private contractors', Public Administration 85,2, 383-404

Day, P. and R. Klein. 1987. Accountabilities: Five Public Services, London: Tavistock.

Demirag, I. and I. Khadaroo. 2008. 'Accountability and Value for Money in Private Finance Initiative Contracts', Financial Accountability and Management 24, 455-478.

Department of Health. 1989. Working for Patients White Paper London: HMSO 
Department of Health. 1997. New NHS: Modern and Dependable White Paper London: HMSO

Department of Health. 2007. The standard NHS contract for acute hospital services and supporting guidance. London: DH.

Department of Health. 2008. Using the commissioning for quality and innovation (CQUIN) payment framework. London: DH.

Department of Health. 2009. The NHS in England: Operating Framework 2010-2011. London: DH

Dodds, A. and N. Kodate. 2011. 'Accountability, organisational learning and risks to patient safety in England: conflict or compromise?' Health Risk and Society 13, 4, 327-346

Duberley, J., and P. Johnson. 1999. 'Contracting in Local Authorities’ Public Management: An International Journal of Research and Theory $1: 4,531-554$

Donabedian, A. (1980) Explorations in quality assessment and monitoring. Ann Arbor: Health Administration Press

Dunsire, A. 1996. 'Tipping the balance: autopoesis and governance', Administration and Society 299, 312-4

Figueras J, Robinson R, and Jakubowski E. (eds) 2005. Purchasing to Improve Health Systems Performance. Maidenhead: Open University Press.

Hodge, G. and K. Coghill. 2007. 'Accountability in the privatized state', Governance 20, 4, 675-702

Hughes, D.,. Allen, P Doheny, S. Petsoulas C., Roberts J. and. Vincent-Jones P. 2011 NHS Contracts in England and Wales: Changing Contexts and Relationships. Final report, Southampton: NIHR SDO programme

Hughes, D., J. McHale and L. Griffiths. 1996. 'Contracts in the NHS: searching for a model?' in P. Vincent-Jones and D. Campbell (eds), Contract and Economic Organisation: Socio-Legal Initiatives. Aldershot: Dartmouth

Hughes, O. 1998. Public Management and Administration. London: Macmillan 
Jackson, P. 2001. 'Public Sector added value: can bureaucracy deliver?', Public Administration 79,1, 5-28

Jacobs, R., Gravelle, H. and Goodard, M. (2004) Measuring performance: an examination of composite performance indicators Technical Paper 29, York: Centre for Health Economics

Jensen M, and Meckling, W..1976. 'The theory of the firm: managerial behaviour, agency costs and ownership structure', Journal of Financial Economics 3, 4, 305-360

Jessop, R. 2002. The future of the capitalist state. Oxford: Blackwell

Keen, J. and Packwood T. (1995) 'Case Study evaluation', British Medical Journal, 311:444-446.

Lane, JE. 1999. 'Contractualism in the Public Sector', Public Management: An International Journal of Research and Theory 1:2, 179-194

Lavoie, J., A. Boulton and J. Dwyer, J. 2010. 'Analysing contractual environments: lessons from indigenous health in Canada, Australia and New Zealand’, Public Administration 88, 3, 665-679

Le Grand, J. and W. Bartlett (eds) 1993. Quasi Markets and Social Policy. London: Palgrave Macmillan

Leat, D. 1988. Voluntary Organisations and Accountability. London: National Council of Voluntary Organisations

Lonsdale, C., I. Kirkpatrick, K. Hoque. and A. De Ruyter. 2010. 'Supplier behaviour in public contracting in the English agency nursing market', Public Administration 88, 3, 800-818

Loughlin, M. 1992. Administrative Accountability in Local Government. York: Joseph Rowntree Foundation

Macaulay S. 1963. 'Non contractual relations in business' American Sociological Review 28: 55-70

Macneil, I. (1978) 'Contracts: Adjustment of long-term economic relations under classical, neo-classical and relational contract law', Northwestern University Law Review 72, 6, 854-905 
Macneil I. 1981. 'Economic Analysis of Contractual Relations: Its shortfalls and the need for a rich classificatory apparatus', Northwestern University Law Review 75, 1022

Maybin, J., R. Addicott, A. Dixonand J. Storey. 2011. Accountability in the NHS. London: Kings Fund.

Mays, N., L. Jones and A. Dixon. (eds). 2011. Understanding New Labour's market reforms of the English NHS. London: King's Fund

Miles, M. 1979. 'Qualitative data as an attractive nuisance - the problem of analysis', Administrative Science Quarterly 24,4, $590-594$.

Miller, P. and M. Power. 1992. 'Accounting, law and economic calculation' in M. Bromwich and A. Hopwood, A. (eds) Accounting and the Law London: Pitman,

Mulgan, R. 2000. ‘Accountability: an ever-expanding concept?', Public Administration 78, 3), 555-573

National Assembly for Wales Audit Committee. 2008. Minimising Healthcare Associated Infections in NHS Trusts in Wales. Report presented to the National Assembly for Wales, Cardiff: WAG

NHS Wales. 2010. Doing Well, Doing Better: Standards for Health Services in Wales. Cardiff: NHS Wales

Osborne, S. (2006) 'New Public Governance?’ Public Management Review 8(3): 377-387

Ouchi, W. (1979) ‘Markets, Bureaucracies and Clans’ Administrative Science Quarterly 25: 129-41

Palmer, N. and A. Mills. 2003. 'Classical Versus Relational Approaches to Understanding Control on a Contract with Independent GPs in South Africa’, Health Economics 12, 1005-1020.

Petsoulas, C., P. Allen, D. Hughes, P. Vincent-Jones and J. Roberts. 2011. 'The use of standard contracts in the English National Health Service: A case study analysis', Social Science and Medicine 73, 2, 185-192

Reeves, E. 2008. 'The practice of contracting in public private partnerships: transaction costs and relational contracting in the Irish schools sector', Public Administration 86, 4, 969-986 
Reeves, E. 2011. 'The Only Game in Town - Public Private Partnerships in the Irish Water Services Sector', Economic and Social Review 42, 1, 95-111.

Schmid, H., 2003. 'Rethinking the policy of contracting out Social Services to non-governmental organizations' Public Management Review 5:3, 307-323

Scott, C. 2000. 'Accountability in the regulatory state', Journal of Law and Society 27,1, 38-60

Seal, W. and P. Vincent-Jones. 1997. 'Accounting and trust in the enabling of long-term relations', Accounting, Auditing and Accountability Journal 10, 3, 406-431

Secretary of State for Health. 1998. A First Class Service: consultation document on quality in the new NHS HSC 1998/113 London: Department of Health

Sheaff, R., Benson, L., Farbus, L., Schofield, J., Mannion, R., and Reeves, D. (2010). Network resilience in the face of health system reform, Social Science \& Medicine 70.5: 779-786.

Tuohy, C. 2003. 'Agency, contract and governance: shifting shapes of accountability in the health care arena', Journal of Health Politics, Policy and Law 28,2-3, 195-215

Vincent-Jones, P. 2006. The new public contracting: regulation, responsiveness, relationality, Oxford: Oxford University Press

Welsh Assembly Government. 2005. Designed for life: creating world class health and social care for Wales in the 21 st century. Cardiff: Welsh Assembly Government,

West, K. 2005. 'From bilateral to trilateral governance in local government contracting in France', Public Administration 83, 2, 473-492

Welsh Health Circular (WHC) 2008. 004 Contracting for Wales: An all Wales Long Term Agreement Template for NHS organisations for 2008/9. Cardiff: Welsh Assembly Government.

Welsh Health Circular (WHC). 2007. 038 Contracting Arrangements For Wales: The introduction of an All-Wales Model Template for Long Term Agreements between Local Health Boards, Health Commission Wales and NHS Trusts. Cardiff: Welsh Assembly Government. 
Williamson, O. 1985. The Economic Institutions of Capitalism New York: Free Press

Yin, R.K. (2003). Case Study Research: Design and Methods ( $3^{\text {rd }}$, ed.). Thousand Oaks, CA: Sage

Figures 1 and 2 follow. 
Figure 1: The English NHS 2007-10

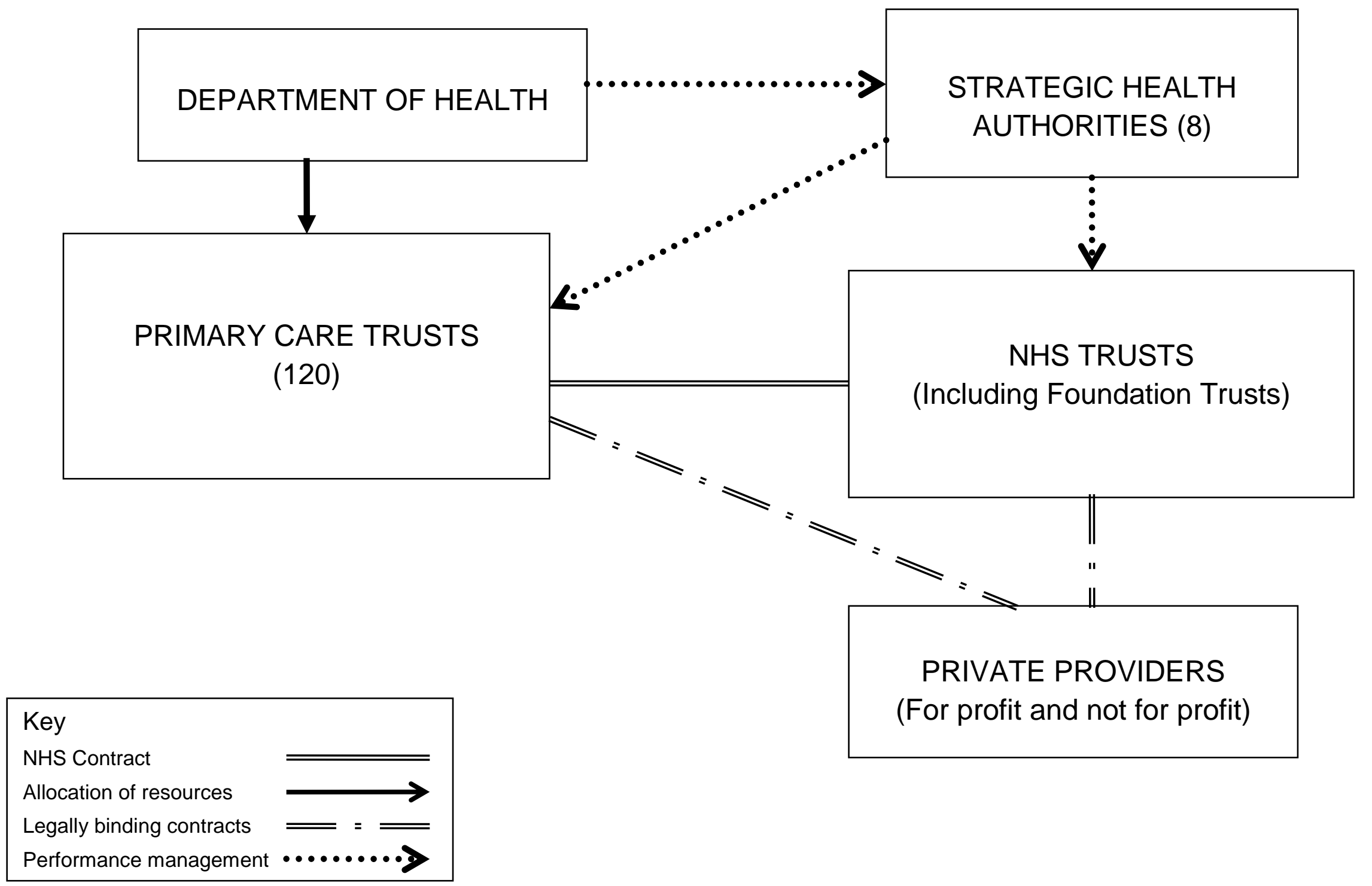


Figure 2: Regional Commissioning of Secondary Care in Wales

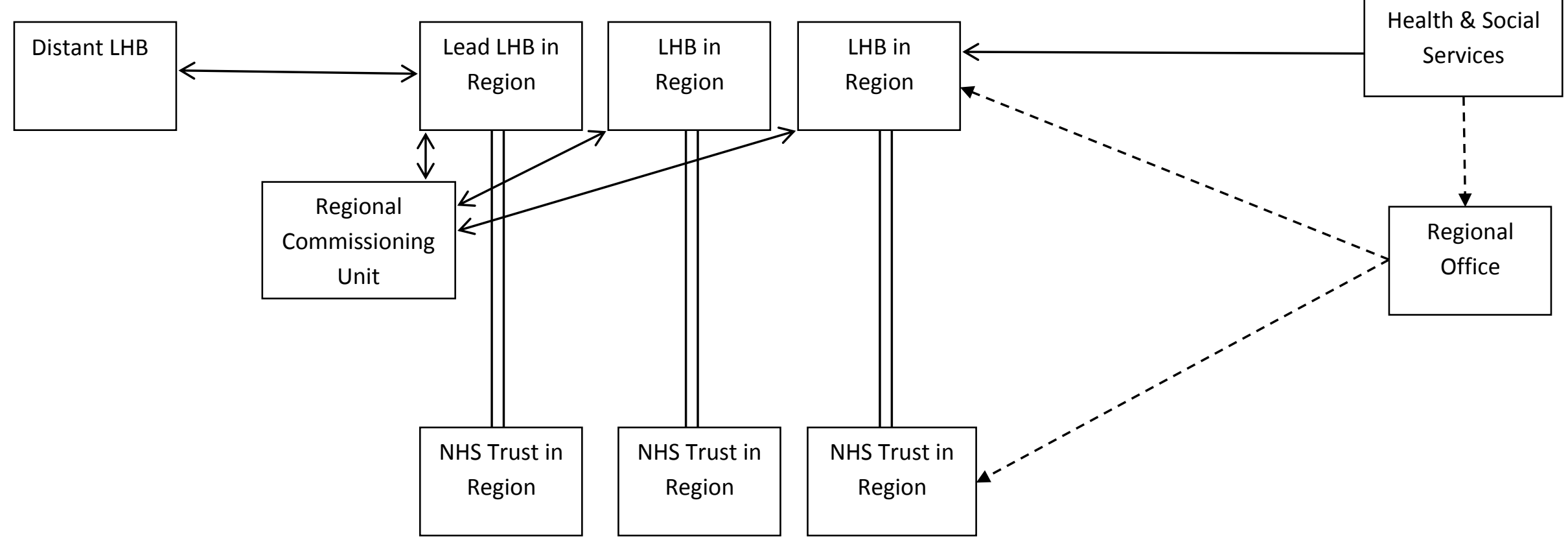

Key

Long-term Agreement (NHS Contract)

Performance Management (AoF)

Allocation of Resources

Collaboration

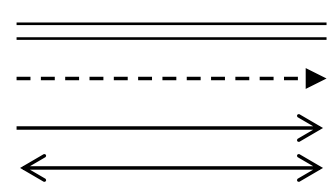

